\title{
Heat Loss During Neonatal Operations
}

\author{
STAVROS TSINGOGLOU and A. W. WILKINSON \\ From The Hospital for Sick Children, Great Ormond Street and Department of Paediatric Surgery, Institute of Child \\ Health, London
}

\begin{abstract}
Tsingoglou, S., and Wilkinson, A. W. (1971). Archives of Disease in Childhood, 46, 452. Heat loss during neonatal operations. The changes in the body and environmental temperatures were measured in 37 babies who were subjected to various operations within three weeks of birth. Factors that cause fluctuations in body temperature have been identified, and means of preventing such changes are described. It is essential to prevent undue exposure and to maintain a microclimate at a suitable temperature round the baby at all stages before, during, and after operation.
\end{abstract}

The vulnerability of the neonate to environmental conditions and the risk of large changes in body temperature by cooling, especially during laparotomy or thoracotomy, are well known. For example, France (1957) reported falls in rectal temperature of up to $8 \cdot 3{ }^{\circ} \mathrm{C}$ during neonatal operations when measures to prevent heat loss were not taken. When the infants were wrapped in cotton wool (Gough, 1960) the average drop in temperature was only $1.56^{\circ} \mathrm{C}$ and only $0.3^{\circ} \mathrm{C}$ if they were put on a warm water mattress (Calvert, 1962). The small baby is also at some risk of abnormal loss of heat on the journey to and from the operating theatre and especially during the induction of anaesthesia and the process of being put in a suitable position on the operation table. It has been recommended that the temperature and humidity of the operating theatre should be raised enough to prevent undue heat loss by the baby, but this causes so much discomfort and loss of efficiency in those working in the theatre that it is seldom used. After earlier observations in this department (Gough, 1960) various precautions were taken to prevent undue loss of heat before, during, and just after neonatal emergency operations, and this report describes the results of further observations on the effect of such measures.

\section{Methods}

Observations have been made on 37 babies who during the first three weeks after birth were subjected to various operations: thoracotomy 7, laparotomy 18, others 12 (closure of myelomeningocele, ventriculoatrial Holter shunts, anoplasty, etc.) Temperatures over a

Received 15 February 1971 range of $22^{\circ} \mathrm{C}$ to $42{ }^{\circ} \mathrm{C}$, at individual differences of $0.05{ }^{\circ} \mathrm{C}$, were recorded through a variety of thermistor probes on a 12-channel Honeywell 'Electronik 15' potentiometric recorder with a 72-second cycle time. The probes were calibrated in a water bath. Skin temperatures were measured with thermistor probes (Y.S.I. No. 409), secured with elastoplast on the abdominal wall, the shoulder, the outer side of the mid-thigh, and the sole of the foot. Another probe (Y.S.I. No. 402) was inserted $10 \mathrm{~cm}$ into the rectum and one was placed in the axilla, and the arm was then strapped to the trunk ('closed axillary probe'). Two air probes (Y.S.I. No. 405) were used to measure ambient air temperatures in the cubicle and the incubator or operation theatre. During operations one air probe was placed on the operating table $10 \mathrm{~cm}$ from the patient's hip under the towels ('microclimate').

The air probe is so designed, a thermistor surrounded by an open metal framework, that it measures air temperature rather than that of the sheet of aluminium foil which acts as a diathermy electrode and rests on the heating mattress on the operating table. In practice it was found that there was a difference in temperature of $2{ }^{\circ} \mathrm{C}$ between the surface of the mattress and that of the aluminium foil and a similar difference in temperature of $2{ }^{\circ} \mathrm{C}$ between the surface of the foil and the temperature recorded by the air probe, which was the same as that of the mattress.

During transport of the patient to and from the theatre, the probes were disconnected only at the recorder end. Atropine sulphate 0.1 to $0.15 \mathrm{mg}$ was administered by intramuscular injection half an hour before operation; there was no subsequent change in rectal or axillary temperature.

Transport. Six babies aged from 3 to 21 days, who before operation were nursed in a cot and dressed in an open-backed gown and nappy, were wrapped in two layers of cotton blanket and were carried to the theatre 
by a nurse. The temperature of one of these babies fell $0 \cdot 1{ }^{\circ} \mathrm{C}$, but there was no change in the others.

All the other babies were covered up to the shoulders with one layer of Gamgee and were transferred to theatre in an incubator. The average time in transit was 10 minutes (range 8-16 $\mathrm{min}$ ). The average temperature of the incubator before disconnexion was $32{ }^{\circ} \mathrm{C}$ (range $\left.29 \cdot 2-35 \cdot 6{ }^{\circ} \mathrm{C}\right)$. There was no change in rectal or axillary temperature in 6 out of 19 babies; in 6 of these temperatures fell 0.1 to $0.5^{\circ} \mathrm{C}$ (mean $0.2^{\circ} \mathrm{C}$ ), and in 7 there was a rise between 0.05 and $0.3{ }^{\circ} \mathrm{C}$ (mean 0.12 ${ }^{\circ} \mathrm{C}$ ). There was an average fall of $0.76{ }^{\circ} \mathrm{C}$ (range $\left.0 \cdot 1-2 \cdot 0{ }^{\circ} \mathrm{C}\right)$ in the temperature of the skin of the soles of the foot.

Similar small changes in rectal and axillary temperature occurred after operation, during transport from the theatre to the ward, when the incubator temperature averaged $29^{\circ} \mathrm{C}$ (range $28-35^{\circ} \mathrm{C}$ ), but the temperature of the sole of the foot, which generally rose during operation, fell between $0.3{ }^{\circ} \mathrm{C}$ and $5.1{ }^{\circ} \mathrm{C}$ (mean $1.52{ }^{\circ} \mathrm{C}$ ) (Fig. 1).

Induction of anaesthesia and preparation on operating table. After breathing $100 \%$ oxygen for a few seconds, all patients were intubated and anaesthesia was then induced with oxygen $50 \%$, nitrous oxide, $50 \%$, Halothane up to $2 \cdot 5 \%$. A needle (21 S.W.G.) was inserted into a suitable vein on the scalp or the back of the hand, and attached to a three-way tap, and a muscle relaxant was injected if necessary. The time spent on induction varied from 4 to 30 minutes (average 11 minutes).

In 7 children who were anaesthetized in the anaesthetic room, with a room temperature of 21 to $24{ }^{\circ} \mathrm{C}$, rectal temperature fell between 0.1 and $0.65{ }^{\circ} \mathrm{C}$ (average $0.34^{\circ} \mathrm{C}$ ). 5 of them had previously been nursed in a cot, and during induction they lay naked on the trolley.

All the other babies were transferred into the operating theatre in their incubators, and were transferred there from the incubator directly to an electric mattress on the table and covered with their own piece of Gamgee before intubation and the induction of anaesthesia.

During the period of induction (in 22 measurements) while the theatre temperature was between $22{ }^{\circ} \mathrm{C}$ and $27{ }^{\circ} \mathrm{C}$ (average $25 \cdot 08^{\circ} \mathrm{C}$ ) and the microclimate was between 27.2 and $38.5{ }^{\circ} \mathrm{C}$ (average $32.42{ }^{\circ} \mathrm{C}$ ), rectal or axillary temperatures generally fell. With the exception of 4 children-3 were in equilibrium, 1 gained $0.55^{\circ} \mathrm{C}$ - the temperature fell between 0.1 and $0.35^{\circ} \mathrm{C}$ (average $0.2{ }^{\circ} \mathrm{C}$ ). If covered continuously with Gamgee, the abdominal temperature rose between 0.15 and $2.0{ }^{\circ} \mathrm{C}$ (average $0.79^{\circ} \mathrm{C}$ ). The temperature of the sole, with the exception of 3 cases ( 2 in equilibrium, 1 fell $0.05^{\circ} \mathrm{C}$ ), rose an average of $1.02{ }^{\circ} \mathrm{C}$ (range 0.6 to $2.0{ }^{\circ} \mathrm{C}$ ) (Fig. 1 and 2).

During preoperative preparation which lasted from

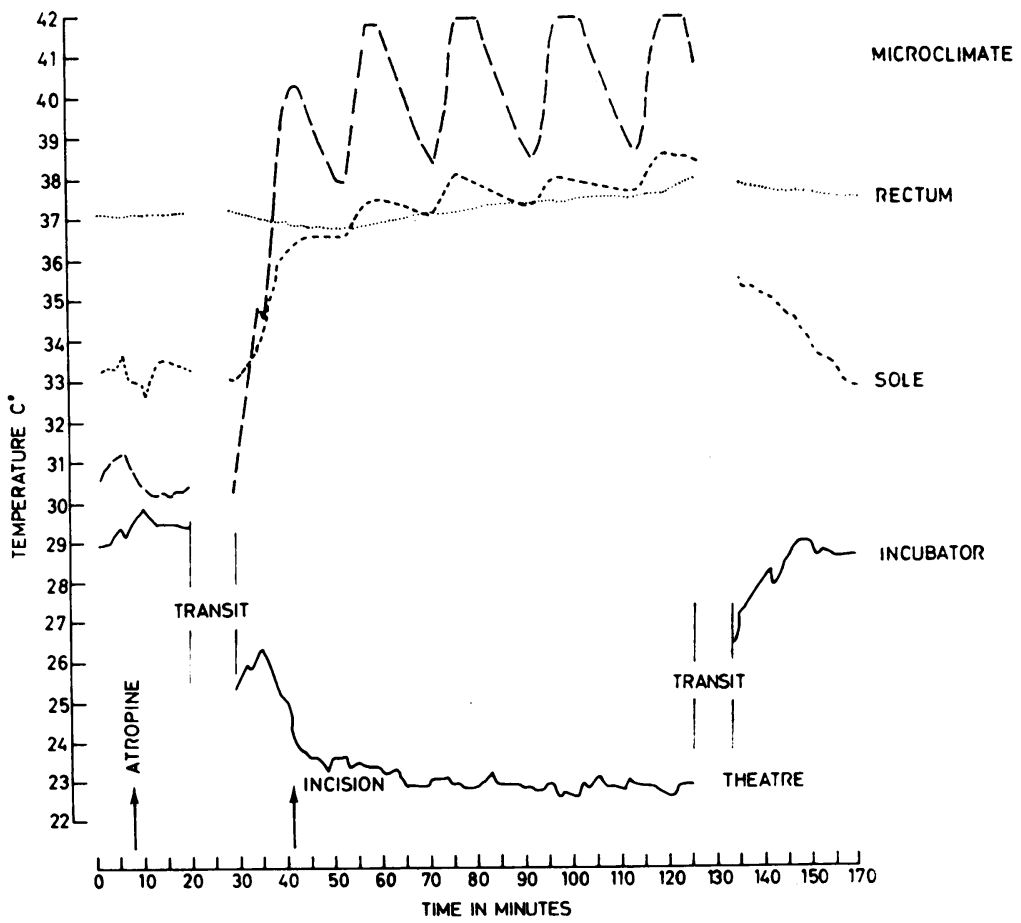

FIG. 1.-Temperature changes during thoracotomy, division, and closure of tracheo-oesophageal fistula and primary oesophageal anastomosis. Female, weight 2,700 g. 


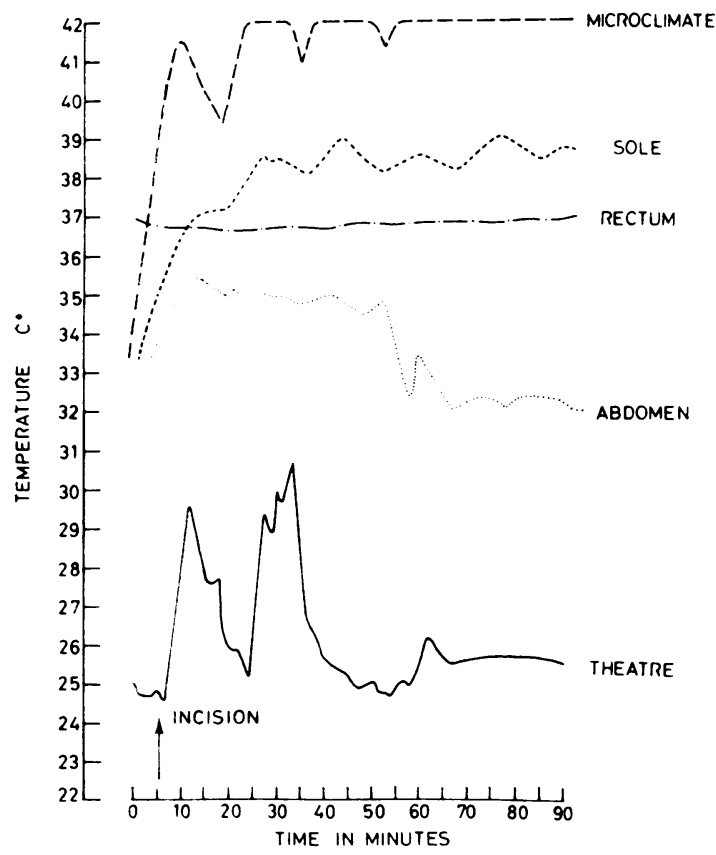

FIG. 2.-Temperature changes during laparotomy, biopsy, and transverse colostomy for Hirschsprung's disease. Male, weight 4,000 g.

2 to 10 minutes (average $4 \cdot 7$ minutes) the patient was positioned, covered with the Gamgee below the hips, and frequently the upper part of the thorax and neck were covered with cotton wool. The skin was cleaned with $0.5 \%$ Hibitane in $70 \%$ methylated spirit at $36-38{ }^{\circ} \mathrm{C}$. All cleaning solutions and intravenous fluids except blood were kept in a cupboard at a temperature of between 40 and $43^{\circ} \mathrm{C}$.

During this time, while the microclimate temperature was steadily rising to between 29 and $40^{\circ} \mathrm{C}$ (average $34.49{ }^{\circ} \mathrm{C}$ ), the rectal or axillary temperature fell between 0.1 and $0.4{ }^{\circ} \mathrm{C}$ (average $0.18{ }^{\circ} \mathrm{C}$ ) in all except 7 patients who remained in equilibrium. The abdominal temperature fluctuated with a tendency to rise and the sole temperature (except in one case which remained unchanged) rose between $0.05{ }^{\circ} \mathrm{C}$ and $2.2{ }^{\circ} \mathrm{C}$ (average $0.69^{\circ} \mathrm{C}$ ) (Fig. 1 and 2 ).

\section{Operation}

(a) Environmental conditions. The average theatre temperatures during operation were $22 \cdot 7$ to $28.0{ }^{\circ} \mathrm{C}$ (overall average $25 \cdot 67^{\circ} \mathrm{C}$ ), but during each operation there was little variation, except in 3 cases when it was between 2 and $3^{\circ} \mathrm{C}$. The relative humidity, measured with the Edney hair hygrometer, remained steady during operation and ranged from $32 \%$ to $62 \%$ (average $43 \%$ ). The ventilation system changed the theatre air 17 times an hour throughout all operations. The number of people present in the theatre varied from 7 to 18 . The two electric blankets used were controlled to operate up to $42{ }^{\circ} \mathrm{C}$ but their performance was very variable. The average microclimate temperature varied widely during operations and between operations from 32.8 to $42.0{ }^{\circ} \mathrm{C}$ (mean $37.29^{\circ} \mathrm{C}$ ). The child lay on a sheet of aluminium foil which acted as the diathermy pad.

(b) Temperature changes during operations (Fig. 1 and 2). The overall changes in rectal or axillary temperature during operations are shown in the Table. During the

TABLE

Change in Rectal Temperature during Operation

\begin{tabular}{|c|c|c|}
\hline $\begin{array}{c}\text { Changes in Rectal } \\
\text { Temperature }\end{array}$ & $\begin{array}{c}\text { No. of } \\
\text { Patients }\end{array}$ & $\begin{array}{l}\text { Mean and Range of } \\
\text { Changes }\end{array}$ \\
\hline $\begin{array}{ll}\text { Net rise .. } & . . \\
\text { No net change } \\
\text { Net fall }\end{array}$ & $\begin{array}{r}18 \\
4 \\
15\end{array}$ & $\begin{array}{l}\text { Mean }+0.51^{\circ} \mathrm{C} \\
\text { Range }+0.05^{\circ} \mathrm{C} \text { to } 1.2 \mathrm{C} \\
\pm 0.05^{\circ} \mathrm{C} \\
\text { Mean- } 0.61^{\circ} \mathrm{C} \\
\text { Range- } 0.10^{\circ} \mathrm{C}-1.55^{\circ} \mathrm{C}\end{array}$ \\
\hline
\end{tabular}

first 1 to 5 minutes the rectal temperature fell between 0.1 and $0.2{ }^{\circ} \mathrm{C}$. Subsequently the rectal temperature was most influenced by the temperature of the microclimate. The closed axillary temperature followed a pattern almost identical to the rectal temperature and when differences occurred they were of the order of $0 \cdot 2{ }^{\circ} \mathrm{C}$. During thoracotomy, changes in the temperature of the abdominal skin followed a similar pattern to those in rectal temperature, being under the influence of the microclimate temperature. In all other operations, if the skin of the monitored area did not become wet, its temperature was influenced by other environmental factors, such as surgical drapes, lighting, room t 3 mperature, and proximity to the electric blanket. On such occasions the difference between rectal temperature and skin temperature increased by the end of the operation between $0.1{ }^{\circ} \mathrm{C}$ and $1.0{ }^{\circ} \mathrm{C}$.

In 19 patients the temperature of the skin of the soles rose between 0.1 and $5.0{ }^{\circ} \mathrm{C}$ (average $1.91^{\circ} \mathrm{C}$ ) during the first few minutes of operation, but subsequently it was most influenced by the temperature of the microclimate. In one other patient, who had an anoplasty in the lithotomy position, there was a fall of $0.45^{\circ} \mathrm{C}$ in the temperature of the soles.

Fluctuations in ambient theatre temperature of more than $3^{\circ} \mathrm{C}$ did not affect body temperature (see Fig. 2). On two occasions, however, when the theatre temperature was $22 \cdot 7{ }^{\circ} \mathrm{C}$ and $23 \cdot 1{ }^{\circ} \mathrm{C}$ and the microc'imate temperature was around $40{ }^{\circ} \mathrm{C}$, body temperature rose. By contrast in 2 other cases, when the theatre temperature was around $28^{\circ} \mathrm{C}$ and the microclimate was between 34 and $36{ }^{\circ} \mathrm{C}$, rectal temperature fell. In 2 other patients, when the theatre temperature was $28{ }^{\circ} \mathrm{C}$ and the microclimate temperature was $37^{\circ} \mathrm{C}$, the body temperature rose by $1.0{ }^{\circ} \mathrm{C}$ and $1 \cdot 2{ }^{\circ} \mathrm{C}$. Ignoring other factors, the average theatre temperature was $25 \cdot 82{ }^{\circ} \mathrm{C}$ in patients whose rectal temperature rose and $25.48{ }^{\circ} \mathrm{C}$ in those whose temperature fell or did not change, while 
the average microclimate temperatures were $38 \cdot 17{ }^{\circ} \mathrm{C}$ and $36.46^{\circ} \mathrm{C}$, respectively.

The duration of the operation affected body temperature only when the microclimate temperature was too high or too low. We did not find any relation between body temperature and the type of anaesthetic agent which was used. An intravenous infusion was maintained at a very slow rate so that anaesthetic agents might be injected or blood transfused if it was necessary. The rapid injection of $10 \mathrm{ml}$ cold blood was followed within 2 minutes by a fall of $0 \cdot 1{ }^{\circ} \mathrm{C}$ in rectal temperature in 7 patients, but this did not occur when the blood in the syringe was first warmed on the electric blanket. When a lead diathermy pad wetted with saline was used instead of paper-backed aluminium foil body temperature fell by 0.1 to $0.6^{\circ} \mathrm{C}$ but later slowly rose again. There were small drops of 0.2 to $0.5{ }^{\circ} \mathrm{C}$ when $x$-ray cassettes were placed under infants during operations.

In general the site and nature of the operation had little effect on the body temperature of babies who were treated as we have described. On 3 occasions however when the drapes became wet during laparotomy the temperature of the abdominal skin fell $2-2 \cdot 5^{\circ} \mathrm{C}$ and the rectal temperature by $0.2-0.6{ }^{\circ} \mathrm{C}$. There were small rises in rectal temperature in all but one of the babies subjected to thoracotomy. In 3 out of 4 babies with myelomeningocele there was a fall in rectal temperature $\left(0 \cdot 6-0.9{ }^{\circ} \mathrm{C}\right)$ during operation, but all were supported on sandbags under the pelvis and upper thorax and were not in contact with the blanket. In the fourth baby the temperature rose by $0.05{ }^{\circ} \mathrm{C}$ but the microclimate was about $42{ }^{\circ} \mathrm{C}$ throughout the operation.

The ages of the patients varied from 23 hours to 21 days $(19,<48$ hours; $10,3-7$ days ; 8, 7-21 days), and their weights from $1.45 \mathrm{~kg}$ to $4.00 \mathrm{~kg}(5,<2 \mathrm{~kg} ; 16$, $2-3 \mathrm{~kg} ; 16,>3 \mathrm{~kg})$. The largest fluctuations in temperature both up and down were found in the first 48 hours of life and in babies who weighed less than $2 \mathrm{~kg}$.

(c) Temperature after operation. The rectal temperature at the end of the operation in 17 babies was between 36.5 and $37.5{ }^{\circ} \mathrm{C}$ (mean $36.92{ }^{\circ} \mathrm{C}$ ). In 7 it was higher than $37.5^{\circ} \mathrm{C}$ (mean $38.38^{\circ} \mathrm{C}$ ), highest $39.5^{\circ} \mathrm{C}$ ) and in the remaining 13 it was below $36.5^{\circ} \mathrm{C}$ (mean $35.95{ }^{\circ} \mathrm{C}$, lowest $35.30^{\circ} \mathrm{C}$ ).

There were only small changes in temperature during operations, but it is clear that some patients were taken to the operating theatre with subnormal temperatures. The postoperative period was smooth except in one child with septicaemia (temperature $39.5^{\circ} \mathrm{C}$ ) who had to be cooled after operation because the temperature continued to rise. The temperature of the skin of the sole was higher than the rectal temperature during operation but after operation fell below the rectal temperature (Fig. 1).

\section{Discussion}

Variations in environmental temperature and humidity which may be unnoticed by the well-clad adult may have severely adverse effects on the naked neonate. When the difference between the rectal and environmental temperature of the neonate is more than 2 to $3{ }^{\circ} \mathrm{C}$ the baby must generate more heat to maintain body temperature. Hill and Rahimtulla (1965) and Scopes (1966) found that the oxygen consumption of a naked premature infant might rise $25 \%$ when the environmental temperature fell $2{ }^{\circ} \mathrm{C}$. Among the neonates who require emergency surgical treatment soon after birth, there is an increasing proportion with more than one anomaly, unfortunately often in the cardiovascular system, or with pneumonia, or who are small or prematurely born. There is a limit to what the skill of the nursing staff and of anaesthetists and surgeons can do to reduce the morbidity and mortality among such patients, but the adverse effects of cooling and unnecessary exposure to a harsh environment are still not widely enough realized.

Even with our careful supervision of the rigorous precautions we have described, small drops in body temperature occurred and if the worst of these had all affected the same baby there would have been a total fall in body temperature of $2 \cdot 1^{\circ} \mathrm{C}$. There is no justification for exposing a neonate naked either in the anaesthetic room or in the operation theatre at an ambient temperature of 21 to $24{ }^{\circ} \mathrm{C}$, nor is there any good reason for exposing the operating team to an ambient temperature of 25 to $30{ }^{\circ} \mathrm{C}$ to protect the baby if an efficient and reliable heating mattress is used on the operating table. Even the best mattress is liable to become unreliable and some accurate means of measuring the temperature of the baby and his immediate environment under the drapes is essential for safety. It is evident that with the method we have used, the cooling effect of opening the chest or abdomen and of limited exposure of the viscera and bowel can be completely compensated for by the warm microclimate and the heated mattress, which are more important factors than even the theatre temperature.

Skin damage has not been observed or reported with a mattress the temperature of which does not exceed $42{ }^{\circ} \mathrm{C}$. The temperature of the mattress should be regulated according to the rectal temperature which should be measured at least every 15 minutes. The range of working temperature of the electric mattress should preferably be 37 to $42{ }^{\circ} \mathrm{C}$; any tendency for the body temperature to rise above $37^{\circ} \mathrm{C}$ can then be counteracted by switching off the blanket. When a lower range of working temperature $32-35{ }^{\circ} \mathrm{C}$ is used and the body temperature falls other methods of heating the baby must be used, such as increasing ambient temperature in the operating theatre usually to a degree which is uncomfortable for those working in it.

Before operation the baby should be protected 
with some kind of fabric such as Gamgee because repeated opening of the incubator ports for $x$-ray and other examinations of the baby, blood sampling, gastric aspiration, and so on results in lowering of the ambient temperature inside the incubator. Baum and Scopes (1968) found that heat loss could be avoided by wrapping wet newborn babies in a sheet of polyester laminated on the inside with a thin layer of aluminium. We have found that this method is not practicable for neonatal surgical patients.

When very rarely large quantities of blood have to be transfused, the microclimate may have to be maintained at a higher temperature to prevent cooling of the baby.

\section{REFERENCES}

Baum, J. D., and Scopes, J. W. (1968). The silver swaddler. Lancet, 1, 672.

Calvert, D. G. (1962). Inadvertent hypothermia in paediatric surgery. Anaesthesia, 17, 29.

France, G. G. (1957). Hypothermia in the newborn: body temperatures following anaesthesia. British fournal of Anaesthesia, 29, 390.

Gough, M. H. (1960). Temperature changes during neonatal surgery. Archives of Disease in Childhood, 35, 66.

Hill, J. R., and Rahimtulla, K. A. (1965). Heat balance and the metabolic rate of new-born babies in relation to environmental temperature; and the effect of age and of weight on basal metabolic rate. Fournal of Physiology, 180, 239.

Scopes, J. W. (1966). Metabolic rate and temperature control in the human baby. British Medical Bulletin, 22, 88.

Correspondence to Professor A. W. Wilkinson, Institute of Child Health, 30 Guilford Street, London W.C.1.

The following articles will appear in future issues of this journal:

Cretinism: Early Diagnosis and Its Relation to Mental Prognosis. By S. Raiti and G. H. Newns.

Familial Haemophagocytic Reticulosis in First Cousins. By N. R. M. Buist, R. N. Jones, and T. R. Cavens.

Endocarditis in the Neonatal Period. By A. Milford Ward.

Rippling Mattress Worked from Compressed Air Supply. By A. H. Etchells, D. L. Thomas, and D. G. Young.

Endemic Skeletal Fluorosis. By M. Teotia, S. P. S. Teotia, and K. B. Kunwar.

SH (Australia) Antigen in Early Life. By G. C. Turner, A. M. Field, R. M. Lasheen, R. McL. Todd, G. B. B. White, and A. A. Porter.

IgA Deficiency in Children: A Clinical Study with Special Reference to Intestinal Findings. By

E. Savilahti, P. Pelkonen, and J. K. Visakorpi.

Blood Pressure Recording in Children. By M. Long, J. R. Dunlop, and W. W. Holland.

Personal Practice: Hypoglycaemia in Infancy and Childhood. By R. M. Ehrlich.

Effect of Scoliosis on Growth of the Alveoli and Pulmonary Arteries and on the Right Ventricle. By

G. Davies and L. Reid.

Aetiology of Transient Neonatal Diabetes. By R. D. G. Milner, A. W. Ferguson, and S. H. Naidu.

Height and Weight at Menarche and a Hypothesis of Menarche. By R. E. Frisch and R. Revelle.

Cloverleaf Skull and Thanatophoric Dwarfism. Report of Four Cases, Two in the Same Sibship. By

M. W. Partington, F. Gonzales-Crussi, S. G. Khakee, and D. G. Wollin.

The Effects of a Totally Synthetic, Low-phenylalanine Diet on Adolescent Phenylketonuric Patients.

By C. M. McKean.

Gentamicin in Esch. coli gastroenteritis. By M. Coetzee and P. M. Leary.

Familial Occurrence of Single Ventricle. By C. Stevenson, A. Franken, S. Ha-Upala, and J. C. Christian. 